\title{
Non-thermal gliding-arc plasma reforming of dodecane and hydroprocessed renewable diesel
}

William Piavis, Scott Turn, Seyedmohammadali Mousavi

Hawai'i Natural Energy Institute, University of Hawai'i at Manoa, 1680 East-West Road, Post 109, Honolulu, HI 96822, USA

William Piavis: corresponding author. Phone: 808-956-5944, Fax: 808-956-2336, email:

piavis@hawaii.edu

\section{Abstract}

This paper focuses on reforming dodecane and hydroprocessed renewable diesel to hydrogen rich gas in a non-thermal gliding-arc plasma stabilized in a reverse vortex flow reformer. The liquid fuels were directly injected into the reaction chamber using an ultrasonic nozzle and entrained in the reverse vortex flow before passing through the plasma. Initial parametric tests were used to investigate the individual effects of varying power input, steam to carbon ratio, and equivalence ratio on reformer performance. Subsequent factorial tests varied these parameters to identify optimal specific energy requirements. Optimal reforming conditions for dodecane, a model diesel compound, resulted in specific energy requirements of $134.1 \pm 1.1 \mathrm{~kJ} \mathrm{~mol}^{-1} \mathrm{H}_{2}$ produced, a $\mathrm{H}_{2}$ yield of $65.0 \pm 0.02 \%$, and an efficiency of $37.0 \pm 0.02 \%$. Optimal conditions for hydroprocessed renewable diesel resulted in a specific energy requirement of $176.1 \pm 3.8 \mathrm{~kJ} \mathrm{~mol}^{-1} \mathrm{H}_{2}$ produced, a $\mathrm{H}_{2}$ yield of $64.2 \pm 1.7 \%$, and an efficiency of $35.0 \pm 1.0 \%$ at $95 \%$ confidence intervals. Physical operating boundaries due to arc extinction were identified.

\section{Keywords}

Non-thermal plasma, gliding arc reformer, reverse vortex flow reformer, dodecane, hydroprocessed renewable diesel, HRD-76, hydrogen production

\section{Introduction}

Recently, the alternative energy sector has experienced rapid growth because of increasing pressure from climate change awareness, rising fuel costs, and a need for domestic energy security [1, 2]. New technologies have focused on producing energy that is accessible, environmental friendly, sustainable, secure, and can meet current and future projected energy needs [3]. Hydrogen is expected to play a large role in the energy economy of the future as it can be utilized in fuel cell applications, and in the synthesis of alternative fuels $[1,3,4]$. This paper explores the use of a non-thermal reverse vortex flow (RVF) gliding-arc reformer for liquid fuels. Tests were conducted using dodecane as a model diesel compound and hydroprocessed renewable diesel fuel. Parametric tests determined the effects of various system parameters, while factorial tests were utilized for system optimization.

\subsection{Current fuel reforming technologies}


Hydrogen is expected to be a prominent fuel in the future $[1,3,4]$. However current production methods are expensive, require complex and large machinery or costly catalysts, and require an expensive distribution infrastructure $[1,3,5]$. Steam, partial oxidation, and autothermal reforming constitute the major reforming technologies $[2,3]$. Hydrogen production via steam reforming of natural gas utilizes roughly one third of the fuel to support the parasitic energy requirement of the process. Ultimately this leads to an specific energy requirement (SER) of 325 to $354 \mathrm{~kJ} \mathrm{~mol}^{-1}$ of hydrogen produced $[6,7]$.

Since the late 90's, interest in plasma reforming has grown [8]. Plasma reformers can operate in thermal equilibrium or non-thermal equilibrium. Thermal plasma reformers operate at high temperatures $(5,000-10,000 \mathrm{~K})$, require power inputs of $1 \mathrm{~kW}$ to $50 \mathrm{MW}$, require extensive measures to prevent electrode wear $[9,10]$, and are most commonly used for metallurgical applications [11].

Non-thermal reformers can utilize various plasma forms such as glow discharge, corona discharge, silent discharge, dielectric barrier discharge, gliding arc, etc. Non-thermal plasma can operate near room temperature, at lower power inputs than thermal plasmas, and at or near atmospheric pressure [10]. They commonly have a much smaller physical foot print than traditional reforming technologies and can be used in onboard applications [12], all while maintaining high energy densities required for hydrocarbon reforming [13]. Within a non-thermal plasma, electrons exist at high temperatures, ranging from 10,000 to $100,000 \mathrm{~K}$ [2], while the protons and neutrons remain near room temperature $[10,13]$. Intermediate, 'warm' plasmas, however, with gas temperatures ranging from 2,000 to 4,000 $\mathrm{K}$ can also be utilized for controlled gas reforming [11]. Petitpas et al. produced an extensive comparison of plasma technologies highlighting various reformer efficiencies, fuel conversion rates, and energy requirements [2]. Gutsol et. al.'s review of reforming technologies concluded that hydrogen must be produced for less than $109 \mathrm{~kJ} \mathrm{~mol}^{-1}$ [6] to be economically feasible. Many technologies are approaching this point [2].

\subsection{Adaptation to liquid fuels}

Previous work explored parameters affecting the performance and optimization of non-thermal, reverse vortex flow, stabilized gliding-arc plasma reforming of methane [14]. This paper explores the performance and optimization of the same system adapted for the reforming of selected liquid fuels. Liquid fuels can be distributed via existing fuel infrastructure and then reformed to produce hydrogen on site.

The two fuels of particular interest for ship board applications are marine diesel (F-76) and hydroprocessed renewable diesel (HRD-76). Dodecane was chosen as a model liquid diesel compound in the development of a liquid fuel injection system. HRD-76 was the primary biofuel used in the recent Great Green Fleet exercises [15]. Reforming F-76, HRD-76, or their blends, could allow the Navy to transport a liquid fuel that could be reformed into hydrogen rich gas for shipboard applications.

\section{Materials and Methods}


Figure 1

Figure 1 - RVF non-thermal plasma reformer for liquid fuels test bed diagram

Figure 1 shows the test bed for RVF non-thermal, gliding-arc plasma reforming of liquid fuels. The system used for methane reforming previously described [14] was modified to accommodate liquid fuels. Changes to the three major component groups, reactant delivery, reformer and power supply, and product conditioning, are highlighted below.

\subsection{Reactant delivery}

A piston pump (SmoothFlow Pump 100 (LF), Microfluidica, Glendale, WI) provided precise fuel flow control to a nozzle injection system. The fuel is atomized upon injection at the top of the reaction chamber by an ultrasonic nozzle system powered by a digital signal generator (model HT40K50T, Sonaer Ultrasonics, Farmingdale, NY). The system atomized liquid fuel into $25 \mu \mathrm{m}$ diameter droplets using 1.15 to $2.25 \mathrm{~W}$ power input over a range of fuel flow rates from 0.44 to $1.65 \mathrm{ml} \mathrm{min}^{-1}$. Droplet sizes were measured using a phase-Doppler particle sizing system (Aerometrics, Sunnyvale, CA). Increasing power to the nozzle tip decreased the mean droplet diameter while increasing axial and radial droplet velocity, and resulted in liquid accumulation on the reactor walls and/or excessive unreacted fuel directly exiting the reactor. Particles with $25 \mu \mathrm{m}$ diameter were entrained within the interior vortex of the reverse vortex flow, and were transported along the flow lines through the plasma arc.

\subsection{Reformer and power supply}

The power supply for the reactor underwent minor changes when the reformer was adapted for use with liquid fuels. The only change to the power supply section was the substitution of an updated variable transformer (Model 3PN1510B-DVAM, ISE, Inc., Cleveland, OH).

Figure 2

Figure 2 - Non-thermal gliding arc plasma RVF reformer (42 $\mathrm{mm}$ internal diameter) for liquid fuels, dimension in $\mathrm{mm}$.

Figure 2 shows the updated reformer, modified for the introduction of liquid fuels into the reaction chamber. A non-conducting, top electrode mount made from zirconia ceramic (AmZirOx 86, Astro Met Zirconium Oxide, Cincinnati, $\mathrm{OH}$ ) electrically insulated the ultrasonic nozzle from the upper electrode. AmZirOx 86 zirconia ceramic was chosen due to its electrical resistivity, low thermal expansion, and chemical inertness. Removing the upper electrode mount from the Macor top plate allowed radial insertion of the upper electrode into the reaction chamber. The $42 \mathrm{~mm}$ ID quartz tube reactor body is sealed at all mounting points with silicone O-rings.

The stainless steel tangential inlet plate used in the earlier study was replaced by one made of zirconia (AmZirOx 86, Astro Met Zirconium Oxide, Cincinnati, $\mathrm{OH}$ ) to avoid electrical discharge between it and the top electrode. The bottom electrode lead was inserted through a pilot hole on the side of the plate (not shown in Figure 2) and made radial contact with the Inconel bottom electrode. All gas ports were 316 stainless steel Swagelok fittings inserted into the ceramic with pipe thread connections. 
The ultrasonic nozzle was attached to an aluminum mounting plate fixed to the Macor ${ }^{\mathrm{TM}}$ top plate with PTFE threaded rods and sealed with a Kalrez ${ }^{\circledR}$ o-ring.

A funnel shape was added to the bottom of the quartz post reaction chamber to drain any unreformed liquids out of the reactor. A high temperature three-way valve (model MPT100-SS-T-SSS-N-15, Control Resources, Salisbury NC) at the reactor exit directed the product stream into the reformate conditioning and analysis section or into a bypass to exhaust during non-steady state periods. This allowed the system to come to steady state without contaminating the impinger train used for liquid analysis.

\subsection{Reformate conditioning and analysis modifications}

The gas phase analysis section of the test bed remained unchanged. The reformate conditioning system was modified to accommodate liquid fuels.

Unreformed liquid fuel and liquid byproducts were condensed, trapped, and removed from the reformate stream exiting the reactor. Following the post reaction chamber and the bypass valve, the product stream flowed into a set of four, $500 \mathrm{ml}$ stainless steel impingers in series (SN-5C set, Apex Instruments, Apex, NC). The first three contained $100 \mathrm{ml}$ of isopropyl alcohol (A416 2-Propanol Certified ACS Plus, Fisher Scientific, Hanover Park, IL) and the fourth impinger was left empty. Upon exiting the impinger train, the gaseous reformate passed through a coalescing filter (Model 31G, Balston, Haverhill, $\mathrm{MA})$ to remove any remaining aerosol or particulate matter.

For each operating condition the system was allowed to come to steady state with the reformate bypassing the analysis section. Once steady state was reached, reformate was directed through the analysis section for 40 minutes. The reformate stream was analyzed for $\mathrm{CH}_{4}, \mathrm{CO}, \mathrm{CO}_{2}$ (Ultramat 23 , Siemens, Washington, D.C.), $\mathrm{O}_{2}$ (Oxymat $6 \mathrm{E}$, Siemens, Washington, D.C.), and $\mathrm{H}_{2}$ (Calomat $6 \mathrm{E}$, Siemens, Washington, D.C.) by three on-line gas analyzers. Reformate was analyzed every ten minutes by an online gas chromatograph (GC) (Model 14A, Shimadzu, Columbia, MD) equipped with a $1.52 \mathrm{~m} \times 3 \mathrm{~mm}$ Carbonex ${ }^{\mathrm{TM}} 1000$ column (SUPELCO, Bellafonte, PA) and a thermal conductivity detector in accordance with ASTM D1946-90 [16]. After a 40 minute sampling period the flow was diverted to the bypass and exhaust. The impinger train could be removed and replaced prior to characterizing a different reactor operating point.

The final mass and volume of liquid recovered from the impingers was recorded and a sample of the liquid stored for later analysis using a GC (Autosystem GC, Perkin Elmer, Waltham, MA) equipped with a 60 meter capillary column (Rtx-1, 60m-0.53-7 $\mu \mathrm{m}$, Restek Corporation, Bellefonte, PA) and a flame ionization detector.

\subsection{Fuels and composition}

Dodecane and HRD-76 were used to test the liquid reforming performance of the reactor. Dodecane (99.9\% purity, Arcos Organics No. 117595000, Fisher Scientific, Hanover Park, IL) was chosen as a model compound for diesel $[17,18]$. Parametric tests with dodecane were conducted to determine the effects 
of system parameters. Factorial tests were used to approach optimal operating conditions for dodecane and HRD-76.

HRD-76 was provided by the Naval Fuels and Lubricants Cross Functional Team. It was shipped with a bulk composition by mass of $84.63 \%$ carbon and $15.37 \%$ hydrogen, and a density of $0.781 \mathrm{~g} \mathrm{ml}^{-1}$. Figure 3 shows the GC mass spectrometry (MS) analysis of HRD with the $y$-axis truncated. $3 \%$ of the peak area is octane, but the large majority of the fuel's components fall between pentadecane and octadecane. Heptadecane composes $24 \%$ of the peak area, and octadecane $18 \%$. Gowdagiri et.al report that HRD-76 has an equivalent hydrocarbon formula of $\mathrm{C}_{15.4} \mathrm{H}_{32.7}$ [19] and molecular weight of $218 \mathrm{~g} \mathrm{~mol}^{-1}$, which corresponds well with the GCMS data. Higher heating value was measured with an adiabatic bomb calorimeter (Model 6200, Parr Instruments, Moline, IL) and found to be $46.7 \pm 0.3 \mathrm{MJ} \mathrm{kg}^{-1}(95 \%$ confidence interval), with a calculated lower heating value of $43.40 \mathrm{MJ} \mathrm{kg}^{-1}$.

Figure 3

Figure 3 - GCMS chromatograph of HRD components

\subsection{System variables}

The following section outlines both the dependent and independent system variables .

Reaction chamber - independent variable - held constant

The geometry of the reaction chamber affects the flow characteristics and the residence time within the reactor.

Electrode gap distance - independent variable - held constant

Increasing the gap distance, the distance between the top electrode and the bottom electrode, increases both the non-thermal properties of the arc and the residence time of the gas within the arc $[13,20]$. Utilizing an optimal electrode gap distance from previous work [14], the gap distance was held constant at $32.5 \mathrm{~mm}$.

Axial exit size - independent variable - held constant

A $12.65 \mathrm{~mm}$ (exit orifice to reaction chamber diameter ratio of 0.30 ) axial exit exhibited the best performance for methane reforming [14]. This same electrode configuration was utilized for the liquid fuel reforming experiments.

Oxygen input - independent variable - held constant

The oxygen flow rate was held constant at $0.56 \mathrm{slpm}$ and the equivalence ratio altered by varying the fuel input.

Nitrogen input - independent variable - held constant

The $\mathrm{N}_{2}$ flow rate was held at $2 \mathrm{slpm}$, and maintained a ratio with the $\mathrm{O}_{2}$ flow equal to that of air.

Fuel input - independent variable - varied over test range

Dodecane input was varied from $0.44 \mathrm{ml} \mathrm{min}^{-1}$ to $1.32 \mathrm{ml} \mathrm{min}^{-1}$, corresponding to equivalence ratios of 0.70 to 0.26 . Subsequent HRD test conditions were based on dodecane test equivalence ratios. The 
equivalence ratio is defined as the oxygen to fuel ratio of the reaction divided by the stoichiometric oxygen to fuel ratio (Equation 1 ) where $\dot{n}$ is the species molar flow rate.

$$
\text { Equivalence Ratio }=\frac{\left(\frac{\dot{n}_{\mathrm{O}_{2}}}{\dot{n}_{\text {fuel }}}\right)_{\text {Reaction }}}{\left(\frac{\dot{n}_{O_{2}}}{\dot{n}_{\text {fuel }}}\right)_{\text {Stoich. }}}
$$

Steam input - independent variable - varied over test range

Steam flow to the reactor was varied from 0.1 to $0.6 \mathrm{~g} \mathrm{~min}^{-1}$. The steam to carbon ratio is reported for each test condition.

Power input - independent variable - varied over test range

Power input directly affects the maximum length of the arc that can be sustained and the number of electrons available drive plasma chemistry.

Reactor temperature, volumetric flow rate, gas composition - dependent variables

The power input level, reactant gas inputs, reactor and electrode geometries and electrode gap distance combine to dictate the reactor temperature, volumetric flow rate, and gas composition. The volumetric flow rate was measured as dry product-gas flow (at standard pressure and temperature) downstream of the reactor. This flow rate can be used as a basis to compute a wet, volumetric flow rate at reactor temperature.

\subsection{Testing Methodology}

Parametric tests on dodecane investigated the system response while altering one independent variable at a time. Equivalence ratio, power input, and steam to carbon ratio were investigated. Initial set points and their range for the parametric tests are presented in Table 1.

Table 1 - Independent variables, initial conditions, and value ranges for parametric tests.

\begin{tabular}{|l|c|c|}
\hline Parameter & Initial Set Point & Parametric Range of Values \\
\hline Reactor Length & $112.4 \mathrm{~mm}$ & fixed \\
\hline Reactor Diameter & $40 \mathrm{~mm}$ & fixed \\
\hline Axial Exit Diameter & $12.7 \mathrm{~mm}$ & fixed \\
\hline Electrode Gap & $35 \mathrm{~mm}$ & fixed \\
\hline Nitrogen Flow & $2 \mathrm{slpm}$ & fixed \\
\hline Oxygen Flow & $0.56 \mathrm{slpm}$ & fixed \\
\hline Dodecane Flow & $0.66 \mathrm{ml} \mathrm{min}$ & 0.44 to $1.32 \mathrm{ml} \mathrm{min}^{-1}$ \\
\hline Equivalence Ratio & 0.47 & 0.70 to 0.23 \\
\hline Steam Input & $0.6 \mathrm{~g} \mathrm{~min}^{-1}$ & 0.1 to $0.6 \mathrm{~g} \mathrm{~min}^{-1}$ \\
\hline Steam : Carbon Molar Ratio & 0.96 & 0.16 to 0.96 \\
\hline Power Input & $180 \mathrm{~W}$ & 140 to $250 \mathrm{~W}$ \\
\hline
\end{tabular}


A $2^{3}$ factorial experimental design (8 points per test) was used to optimize dodecane reforming using SER (see definition in Equation (2)) as the performance variable, i.e. identifying the minimum SER operating point of the process. The SER definition in equation (2) is based on the assumption that CO in the product gas can be used to produce additional $\mathrm{H}_{2}$ using the water gas shift reaction. The input power is measured in $\mathrm{kW}$, and $\dot{n}$ is the molar flow rate in $\mathrm{mol} \mathrm{s}^{-1}$.

$$
S E R=\frac{\text { Input Plasma Power }}{\left(\dot{n}_{\mathrm{CO}}+\dot{n}_{\mathrm{H}_{2}}\right)_{\text {produced }}} \quad \quad\left(\mathrm{kJ} \mathrm{mol}{ }^{-1} \mathrm{H}_{2} \text { produced }\right)
$$

High and low values of operating parameters were selected using the results from the parametric tests as a center point (Table 2). The factorial tests also identified system operating limits and higher order interaction effects between the independent variables. The order of individual test points was randomized and data at each test point were collected four times to provide an average value and estimate error. Reported error and error bars on charts reflect a 95\% confidence interval.

Based on the optimal operating conditions for dodecane a $2^{2}$ factorial test investigated HRD-76 reforming while minimizing SER. For the HRD factorial treatments, power input was held constant at the maximum value identified from the dodecane factorial tests. The operating values are summarized in Table 2.

Table 2 - Center points and step sizes for dodecane and HRD-76 factorial tests

\begin{tabular}{|c|c|c|c|c|c|c|}
\hline \multirow[b]{2}{*}{ Parameter } & \multicolumn{2}{|c|}{ 1st Dodecane Factorial Test } & \multicolumn{2}{|c|}{ 2nd Dodecane Factorial Test } & \multicolumn{2}{|c|}{ HRD-76 Factorial Test } \\
\hline & Center Pt. & Step Size & Center Pt. & Step Size & Center Pt. & Step Size \\
\hline Fuel Input & $0.66 \mathrm{ml} \mathrm{min}-1$ & $0.11 \mathrm{ml} \mathrm{min}^{-1}$ & $1.32 \mathrm{ml} \mathrm{min}^{-1}$ & $0.11 \mathrm{ml} \mathrm{min}^{-1}$ & $1.27 \mathrm{ml} \mathrm{min}^{-1}$ & $0.11 \mathrm{ml} \mathrm{min}^{-1}$ \\
\hline Steam Input & $0.4 \mathrm{~g} \mathrm{~min}^{-1}$ & $0.1 \mathrm{~g} \mathrm{~min}^{-1}$ & $1.1 \mathrm{~g} \mathrm{~min}^{-1}$ & $0.1 \mathrm{~g} \mathrm{~min}^{-1}$ & $1.1 \mathrm{~g} \mathrm{~min}^{-1}$ & $0.1 \mathrm{~g} \mathrm{~min}^{-1}$ \\
\hline Power Input & $220 \mathrm{~W}$ & $20 \mathrm{~W}$ & $240 \mathrm{~W}$ & $20 \mathrm{~W}$ & $260 \mathrm{~W}$ & NA \\
\hline
\end{tabular}

\subsection{Data Reduction}

Calculation of performance indicators from experimental data conformed to those used by Petitpas et al. [2]. System performance for dodecane parametric tests and factorial tests were characterized by hydrogen yield, fuel conversion, hydrogen selectivity, efficiency, and specific energy requirements. Differentiating reaction products from original fuel components in HRD was not possible, as higher hydrocarbons present in the fuel could react to form smaller molecules also present in the original fuel, eg. octadecane reformed to heptadecane. Therefore system performance indicators for HRD omitted fuel conversion and selectivity.

Hydrogen yield is defined by the number of hydrogen atoms in hydrogen gas in the reformate divided by the total amount of hydrogen atoms in the reactant fuel (Equation 3) [2].

Hydrogen Yield $=\frac{\text { Hydrogen Atoms in } \mathrm{H}_{2} \text { in reformate }}{\text { Hydrogen Atoms in Feed Fuel }}(\%)$ 
Fuel conversion is defined as the amount of fuel converted in the reactor divided by the total fuel input to the system (Equation 4).

Dodecane Conversion $=\frac{\dot{n}_{\text {dodecane in fuel }}-\dot{n}_{\text {dodecane in reformate }}}{\dot{n}_{\text {dodecane in fuel }}} * 100(\%)$

Selectivity is defined as the hydrogen yield divided by the fuel conversion as shown in Equation 5 . This provides an index of the system's ability to reform the fuel into hydrogen with the assumption that unreformed fuel could be recovered, utilized by other processes, or reintroduced into the reformer.

Selectivity $=\frac{\text { moles of } \mathrm{H}_{2} \text { produced }}{13(\text { moles of dodecane converted })} * 100(\%)$

Efficiency is defined in Equation 6 as the amount of hydrogen energy in the reformate divided by the total system energy input from both the plasma and reactant fuel [2].

Efficiency $\eta=\frac{L H V_{H_{2 g a s}} *\left(\dot{m}_{\mathrm{H}_{2}}+\dot{m}_{\text {Co }}\right)_{\text {reformate }}}{\text { Plasma Power }+L H V_{\text {fuel input }} * \dot{m}_{\text {fuel input }}}$

$L H V$ is the lower heating value $\left(\mathrm{MJ} \mathrm{kg}^{-1}\right)$ and $\dot{m}$ is the mass flow rate of a given species. The efficiency definition assumes, according to convention $[2,21]$, that any CO present in the reformate could be converted to $\mathrm{H}_{2}$ by the exothermic water gas shift reaction (Equation 7) [22].

$\mathrm{H}_{2} \mathrm{O}+\mathrm{CO} \rightarrow \mathrm{H}_{2}+\mathrm{CO}_{2} \quad \Delta \mathrm{H}=-41 \mathrm{~kJ} \mathrm{~mol}^{-1}$

\section{Results and Discussion}

Results from the parametric and factorial tests of dodecane and HRD-76 are summarized below.

\subsection{Dodecane testing}

The following sections summarize results from the dodecane tests.

\subsubsection{Dodecane power input parametric test}

Power input was varied parametrically from 120 to $225 \mathrm{~W}$ in nominal $20 \mathrm{~W}$ increments. The highest point was $225 \mathrm{~W}$ instead of 220 due to the sensitivity of power input controls. Below $120 \mathrm{~W}$, a continuous arc could not be maintained.

Parametrically increasing power input had very little effect on hydrogen yield, hydrogen selectivity, fuel conversion, and efficiency as seen in Figure 4. As the power increased the fuel conversion remained relatively constant at $\sim 90 \%$. Gains in hydrogen yield, which rose from 32.1 to $35.73 \%$, and selectivity, which rose from 35.7 to $42.6 \%$, were realized. Increases in $\mathrm{H}_{2}$ and $\mathrm{CO}$ yields maintained efficiency at near constant values of $\sim 19 \%$ across all power input levels. At $120 \mathrm{~W}$ power input, the plasma power corresponded to $23 \%$ of the total energy input (plasma plus fuel), increasing to $37 \%$ at $225 \mathrm{~W}$. The increasing power input to the system yielded increasing specific energy requirements, ranging from 
319.9 to $486.0 \mathrm{~kJ} \mathrm{~mol}^{-1}$ of $\mathrm{H}_{2}$ produced. Therefore the lower the plasma power input to the system the better the reformer performed as measured by SER.

Figure 4

Figure 4 - Dodecane parametric test results for power input. Error bars indicate $95 \%$ confidence interval. Error bars that are not visible are equal in size to the data point symbol.

\subsubsection{Fuel input parametric test}

The fuel input tests effectively decreased the equivalence ratio by increasing the fuel input (Equation 1). Soot formation occurred when the equivalence ratio decreased below 0.25.

Figure 5 shows fuel conversion remained constant at $\sim 95 \%$ while the equivalence ratio decreased. As the fuel input increased the hydrogen yield and selectivity both increased from 34 to $47 \%$ and 36 to $49 \%$ respectively. At 0.29 equivalence ratio, both the hydrogen yield and selectivity were slightly higher than at 0.25 equivalence ratio. Over the equivalence ratio test range, the efficiency varied from 13 to $30.3 \%$ with the latter value measured at equivalence ratio of 0.29 . This is strongly due to the large increase of $\mathrm{H} 2$ and $\mathrm{CO}$ production. At an equivalence ratio of 0.29 and efficiency of $33.2 \%$, the reformate contains $\mathrm{H}_{2}(17.0 \%)$ and $\mathrm{CO}(16.2 \%)$. A significant rise in SER resulted from increasing fuel input while the fuel conversion percentage remained constant. The SER of $763 \mathrm{~kJ} \mathrm{~mol}^{-1}$ of $\mathrm{H}_{2}$ produced at an equivalence ratio of 0.71 decreases to $184 \mathrm{~kJ} \mathrm{~mol}^{-1}$ at 0.25 . However these gains have diminishing returns and approach a lower limit as the equivalence ratio drops below 0.30 .

Figure 5

Figure 5 - Dodecane parametric test results for equivalence ratio. Error bars indicate $95 \%$ confidence interval. Error bars that are not visible are equal in size to the data point symbol.

\subsubsection{Steam input parametric test}

Steam input helps prevent soot formation within the reactor, however the excess water molecules absorb energy introduced to the system [23]. Steam input to the system was varied from 0.1 to $0.6 \mathrm{~g}$ $\min ^{-1}$ corresponding to a steam:carbon molar ratios of 0.16 to 0.96 , respectively.

Figure 6 shows the effects of increasing steam input to the reformer. The increase in steam does little to change the fuel conversion, which remains near $94 \%$, and efficiency, which remains around $17 \%$. Slight gains are realized in hydrogen yield and hydrogen selectivity as the steam input increases. Hydrogen yield increases $18 \%$ (relative) from 28.3 to $33.5 \%$, while selectivity increases by $14 \%$ (relative) from 31.2 to $36.4 \%$. Gains realized over this low range of steam input indicate that steam was a limiting reactant in some $\mathrm{H}_{2}$ producing reactions. Further increases in steam input dilute the plasma power with negative results [14]. These gains are reflected in the SER which decreased from 493 to $434 \mathrm{~kJ} \mathrm{~mol}^{-1}$ of $\mathrm{H}_{2}$ produced. The effect of steam input was further investigated in the factorial treatments. 
Figure 6

Figure 6 - Dodecane parametric test results for steam input. Error bars indicate $95 \%$ confidence interval. Error bars that are not visible are equal in size to the data point symbol.

\subsection{Dodecane factorial tests}

Dodecane reforming was further investigated using a $2^{3}$ factorial experiment design which investigated effects of plasma power input, fuel input, and steam input. The center point and step sizes for the first factorial test were chosen to ensure the reactor system operated (i.e. no soot formation or arc extinction) and to produce measureable differences in the dependent variables. Data from the factorial tests allowed a path of steepest descent to be mapped across the operating response surface toward a set of independent variable control points that minimized SER.

\subsubsection{First dodecane factorial test}

Table 3 shows the effects of independent variables changing between high and low values. Third order effects $(A B C)$ are assumed to be an estimate of the error [24] thus first and second order effects of greater magnitude are significant. None of the control parameters have a significant effect on dodecane conversion, confirming the parametric test results. Increasing power did not affect the performance metrics except for its negative effect on SER; a $20 \mathrm{~W}$ increase in power input increased the SER by $60 \mathrm{~kJ}$ $\mathrm{mol}^{-1} \mathrm{H}_{2}$. Dodecane input significantly increased both hydrogen yield and selectivity, however it did not have a significant effect on either efficiency or SER. Steam input had the greatest effect on all of the metrics. The increase from 0.3 to $0.5 \mathrm{~g} \mathrm{~min}^{-1}$ improved both hydrogen yield and selectivity by $13 \%$, and increased efficiency by $10.5 \%$. The greatest performance gains came in the SER, decreasing by $276 \mathrm{~kJ}$ mol $^{-1} \mathrm{H}_{2}$ produced.

Table 3 - Summary of first dodecane factorial test results

\begin{tabular}{|c|c|c|c|c|c|c|}
\hline & \multirow{4}{*}{$\begin{array}{c}\text { Control } \\
\text { Parameter }\end{array}$} & \multicolumn{5}{|c|}{ Performance Indicator } \\
\hline & & Dodecane & Hydrogen & Hydrogen & & \\
\hline & & Conversion & Yield & Selectivity & Efficiency & SER \\
\hline & & change in $\%$ & change in $\%$ & change in \% & change in $\%$ & change in $\mathrm{kJ} \mathrm{mol}^{-1}$ \\
\hline \multirow{3}{*}{ 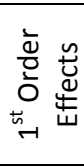 } & A (Power) & 0.45 & 0.70 & 0.54 & -1.35 & $60.16^{1}$ \\
\hline & B (Steam) & 0.36 & $13.25^{1}$ & $13.75^{1}$ & $10.47^{1}$ & $-276.51^{1}$ \\
\hline & C (Fuel) & 1.27 & $4.81^{1}$ & $4.45^{1}$ & 1.45 & -39.44 \\
\hline \multirow{3}{*}{ 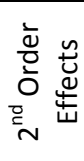 } & $A B$ & -1.16 & -2.47 & -1.97 & -1.64 & 3.07 \\
\hline & $A C$ & 0.98 & 2.39 & 2.07 & 1.15 & -39.48 \\
\hline & $\mathrm{BC}$ & -1.18 & -1.77 & -1.33 & -0.80 & 32.76 \\
\hline $3^{\text {rd }}$ & $A B C$ & -1.25 & -2.34 & -1.85 & -1.32 & 42.32 \\
\hline
\end{tabular}

${ }^{1}$ Indicates significant effect

To move toward operating conditions that improve (reduce) the SER, a path of steepest descent was calculated from the results of the first factorial test. As shown in Table 2, the path pointed toward a 
center point for the second factorial tests characterized by increased steam input, increased dodecane input, and a slight increase in arc power input.

\subsubsection{Second dodecane factorial test}

The second factorial test point with high dodecane and steam inputs, and low power input, experienced multiple failures due to arc extinction. While the arc was extinguished, unreformed fuel passed through the reactor and into the impingers. Therefore the impinger data needed to calculate dodecane conversion and selectivity was not available. However, the GC and online gas analyzers provided reformate gas stream composition when the arc was established and the remaining metrics could be calculated. Table 4 shows the system responses from the second factorial test. Only dodecane input continued to have a significant effect on the system performance. Changing levels of power and steam input with respect to the center point no longer had an effect on system performance. Based on the results of the second factorial test, the path of steepest descent for SER required increasing dodecane input with constant steam and power inputs. 
Table 4 - Second dodecane factorial test results

\begin{tabular}{|c|c|c|c|c|c|c|}
\hline & \multirow{4}{*}{$\begin{array}{c}\text { Control } \\
\text { Parameter }\end{array}$} & \multicolumn{5}{|c|}{ Performance Indicator } \\
\hline & & Dodecane & Hydrogen & Hydrogen & & \\
\hline & & Conversion & Yield & Selectivity & Efficiency & SER \\
\hline & & change in $\%$ & change in $\%$ & change in $\%$ & change in \% & change in $\mathrm{kJ} \mathrm{mol}^{-1}$ \\
\hline ¿ & A (Power) & NA & 3.88 & NA & 0.34 & 18.85 \\
\hline के & B (Steam) & NA & -3.07 & NA & -2.35 & 13.87 \\
\hline $\overrightarrow{\vec{t}_{r}} \overrightarrow{4}$ & C (Fuel) & NA & 3.66 & NA & 3.30 & $-37.79^{1}$ \\
\hline$\frac{\grave{d}}{0}$ & $A B$ & NA & -2.85 & NA & -1.56 & 5.30 \\
\hline ț & $A C$ & NA & -3.36 & NA & -1.90 & 9.47 \\
\hline$N^{4}$ & $\mathrm{BC}$ & NA & -0.14 & NA & -0.09 & -0.12 \\
\hline $3^{\text {rd }}$ & $A B C$ & NA & -6.36 & NA & -3.52 & 17.57 \\
\hline
\end{tabular}

\subsubsection{Final path of steepest descent and optimum}

Figure 7 shows the last path of steepest descent, which terminated at the optimal operating condition for dodecane reforming. The optimal reactor operating point was defined by an input of $2 \mathrm{slpm} \mathrm{N}_{2}$ and $0.26 \mathrm{slpm} \mathrm{O}_{2}$, power input of $240 \mathrm{~W}$, fuel input of $1.65 \mathrm{ml} \mathrm{min}^{-1}$ of dodecane (EQ ratio $=0.18$ ), and steam input of $1.0 \mathrm{~g} \mathrm{~min}^{-1}\left(\mathrm{~S}: \mathrm{C}\right.$ ratio $=0.63$ ). These inputs yielded a SER of $134.1 \mathrm{~kJ} \mathrm{~mol}^{-1} \mathrm{H}_{2}$ produced, a hydrogen yield of $65 \%$, and an efficiency of $37 \%$. Throughout the path of steepest descent the SER continually dropped while the hydrogen yield and efficiency remained nearly constant. Continuing beyond this point on the path of steepest descent was unsuccessful due to extinction of the arc.

The $37 \%$ efficiency at the operating conditions identified by minimizing SER can be compared to the efficiency predicted by thermodynamic equilibrium. The state of the reactant system was described using the $\mathrm{N}_{2}, \mathrm{O}_{2}, \mathrm{C}_{12} \mathrm{H}_{26}$, and $\mathrm{H}_{2} \mathrm{O}$ input flowrates detailed above, a mass averaged input temperature of $50{ }^{\circ} \mathrm{C}$, and $0.1 \mathrm{MPa}$ pressure. The change in enthalpy between reactants and products was based on the $240 \mathrm{~W}$ power input to the plasma arc. Reactant flow rates and arc power were converted to units of moles and Joules using a common time basis. The product composition at equilibrium, calculated using FactSage $^{\mathrm{TM}}$ (CRCT, Montreal, Quebec, Canada), yielded an efficiency of $77 \%$, with $86 \%$ of the input carbon predicted to be present as $\mathrm{CO}$ and the remainder (>13\%) largely present as $\mathrm{CH}_{4}, \mathrm{CO}_{2}$, and solid $\mathrm{C}$. Differences between the measured and equilibrium efficiencies are the result of non-idealities in the plasma system such as heat loss, incomplete mixing of reactants, and inadequate reaction time. This single-pass reactor efficiency would be improved by recovering and recycling unreacted liquid hydrocarbons (described in the next section) as might be expected to occur in a fully integrated reformer unit. Gallagher et al. [12] reported $~ 35 \%$ efficiency for a lab scale plasmatron reformer using 
n-tetradecane at an oxygen to carbon reactant ratio of 0.9 , similar to the conditions reported here as optimal conditions.

Figure 7

Figure 7 - Final dodecane path of steepest descent and optimal operating condition based on minimized SER. Error bars indicate 95\% confidence interval. Error bars that are not visible are equal in size to the data point symbol.

\subsubsection{Impinger Liquid Analysis}

Analysis results of the liquid product recovered from impingers downstream of the reactor for test conditions of $0.55 \mathrm{ml}$ dodecane $\mathrm{min}^{-1}$, steam input of $0.3 \mathrm{~g} \mathrm{~min}^{-1}$, and power input of $200 \mathrm{~W}$, are presented in Figure 8. In addition to unreacted dodecane, six alkenes from 1-hexene to 1-undecene were identified and quantified. Concentrations determined from the GC-FID analysis and the impinger liquid volumes were used to calculate analyte mass. Figure 9 summarizes the distribution of dodecane input carbon among reforming products. The alkene species from Figure 8 as a group (Alkenes) in Figure 9 account for $1.3 \%$ of the input carbon. Identified products accounted for $96.3 \%$ of the carbon input to the system. C3 to C5 hydrocarbons were not measured in either the GC-TCD or GC-FID analysis due to co-elusion with the IPA/acetone trapping solution.

Figure 8

Figure 8 - TCD analysis of liquid samples from impingers 1 - 4. IPA/acetone and dodecane saturated the detector. $1.54 \mathrm{~g}$ of unreformed dodecane was recovered in the impingers, analysis was performed at $10 \%$ dilution.

Figure 9

Figure 9 - Distribution of dodecane input carbon among measured products.

\subsection{HRD-76 testing}

Based on the parametric and factorial test results for dodecane, a factorial test was performed to identify the optimal SER reactor operating conditions for HRD-76.

\subsubsection{Reaction chamber insulation}

During the preliminary HRD-76 tests a cloud of fuel vapor was observed in the top of the reaction chamber. Insulation was added to the top section of the reaction chamber, above the upper electrode mount to improve vaporization. Tests were conducted before and after the insulation was added to the reaction chamber with operating conditions of $260 \mathrm{~W}, 1 \mathrm{~g} \mathrm{~min}^{-1}$ of steam input, and $1.16 \mathrm{ml} \mathrm{min}$ of $^{-1}$ HRD. Prior to adding insulation, the average SER was $218.7 \pm 2.5 \mathrm{~kJ} \mathrm{~mol}^{-1}$ of $\mathrm{H}_{2}$. With the added insulation on the reactor, this operating point was revisited intermittently throughout the ensuing test campaign to provide an indicator of performance repeatability. Using SER data from 12 independent measurements yielded an average value of $183.3 \pm 4.5 \mathrm{~kJ} \mathrm{~mol}^{-1}$ of $\mathrm{H}_{2}$ produced or $2.5 \%$ error. 


\subsubsection{HRD-76 factorial test}

Based on dodecane test results, a $2^{3}$ factorial experiment was designed for the HRD-76 optimization with power input centered at $240 \mathrm{~W}$ and a $20 \mathrm{~W}$ step size. However, the system could not operate at $220 \mathrm{~W}$ due to arc extinction. Power input was removed as a variable in the optimization and the factorial test redesigned to investigate steam and HRD-76 (equivalence ratio) inputs while holding power constant at $260 \mathrm{~W}$ (see Table 2).

Figure 10

Figure 10 - Results of first factorial test for HRD. The darkened symbols show the high steam input points and lighter symbols show the low steam input points. Error bars indicate $95 \%$ confidence interval. Error bars that are not visible are equal in size to the data point symbol.

Figure 10 and Table 5 present the results from the HRD-76 factorial tests. In general the efficiency for the system does not vary greatly from point to point, but trends lower than the efficiency of dodecane at similar equivalence ratios. Increasing fuel input greatly improves system SER performance.

To interpret the data in Table 5, second order effects (AB) were used as indicators of error to judge the significance of lower order effects [20]. The system appears to be operating near an optimum for steam input, as changes to steam input no longer significantly affect the SER. However, increasing steam input has a negative impact on both hydrogen yield and efficiency. Fuel input has a significant effect on SER and efficiency. Increasing fuel input from $1.16 \mathrm{ml} \mathrm{min}^{-1}$ to $1.38 \mathrm{ml} \mathrm{min}^{-1}$ (decreasing equivalence ratio from 0.26 to 0.22 ) improves both the efficiency and SER, but reduces hydrogen yield.

Table 5 - HRD-76 first factorial treatment system responses

\begin{tabular}{l|c|c|c}
\hline \multirow{2}{*}{$\begin{array}{l}\text { Control } \\
\text { Parameter }\end{array}$} & $\begin{array}{c}\text { Pydrogen Yield } \\
\text { change in \% }\end{array}$ & $\begin{array}{c}\text { Efficiency } \\
\text { change in \% }\end{array}$ & $\begin{array}{c}\text { SER } \\
\text { change in kJ mol }\end{array}$ \\
\cline { 2 - 4 } A(Steam) & $-3.12^{1}$ & $-1.28^{1}$ & -0.45 \\
B(HRD) & -0.04 & $1.62^{1}$ & $-36.50^{1}$ \\
AB & 1.72 & 0.29 & 6.09 \\
\hline \multicolumn{3}{c}{${ }^{1}$ indicates significant effect } \\
\hline
\end{tabular}

\subsubsection{Optimum and operational boundaries}

The path of steepest descent from the first factorial test held both power and steam at constant values, while increasing fuel input. The power was set at $260 \mathrm{~W}$ in order to ensure reactor operation, while steam was held constant at an input of $1.0 \mathrm{~g} \mathrm{~min}^{-1}$. As the fuel was increased past $1.38 \mathrm{ml} \mathrm{min}^{-1}$, at an equivalence ratio of 0.22 , soot and liquids deposited on the reactor walls, the latter appearing as a tacky brown film. With increasing deposit mass the arc discharged to the deposited material instead of the lower electrode and the test was terminated. 
Thus optimal operating conditions for minimum SER were identified at inputs of $2 \mathrm{slpm}$ of $\mathrm{N}_{2}, 0.56 \mathrm{slpm}$ of $\mathrm{O}_{2}, 1.0 \mathrm{~g} \mathrm{~min}^{-1}$ of steam, $1.38 \mathrm{ml} \mathrm{min}^{-1}$ of HRD-76, and $260 \mathrm{~W}$ of power. At these conditions the reactor operated with an $\mathrm{H}_{2} \mathrm{O}: \mathrm{C}$ ratio of 0.70 , equivalence ratio of 0.21 , SER of $176.1 \mathrm{~kJ} \mathrm{~mol}^{-1}$ of $\mathrm{H}_{2}$ produced, an efficiency of $35.0 \%$, and a hydrogen yield of $64.2 \%$.

\section{Conclusion}

Modifications to the non-thermal plasma reverse vortex flow methane reformer allowed for the reformation of liquid fuels. Ultrasonic atomization of the fuel was used to axially inject fuel into the reformer. Injected fuel vaporized due to elevated temperatures in the reactor, and vapor clouds were eliminated by insulating the upper half of the reaction chamber.

Parametric and factorial tests investigated the effects of varying the power input, dodecane input, and steam input to the system. Dodecane conversion remained fairly constant across all of the tests while the selectivity, hydrogen yield, efficiency, and SER of the system varied greatly. The system was optimized for SER. Decreasing power input, increasing fuel input, and increasing steam input up to a steam:carbon ratio of 0.73 decreased the SER and improved system performance. Optimal SER of 134.1 $\pm 1.08 \mathrm{~kJ} \mathrm{~mol}^{-1} \mathrm{H}_{2}$ produced, with accompanying hydrogen yield of $65.0 \pm 0.02 \%$, and efficiency of $37.0 \pm$ $0.02 \%$ was achieved for dodecane at inputs of $2 \mathrm{slpm} \mathrm{N}, 0.26 \mathrm{slpm} \mathrm{O}_{2}, 240 \mathrm{~W}, 1.65 \mathrm{ml} \mathrm{min}^{-1}$ of dodecane (equivalence ratio $=0.18$ ), with a steam input of $1.0 \mathrm{~g} \mathrm{~min}^{-1}\left(\mathrm{H}_{2} \mathrm{O}: \mathrm{C}\right.$ ratio $\left.=0.63\right)$.

HRD-76 reforming was optimized at SER of $176.1 \pm 3.8 \mathrm{~kJ} \mathrm{~mol}^{-1}$ of $\mathrm{H}_{2}$ produced, a hydrogen yield of 64.2 $\pm 1.7 \%$, and efficiency of $35.0 \pm 1.0 \%$, using operating parameters of $2.0 \mathrm{slpm}$ of $\mathrm{N}_{2}, 0.56$ slpm of $\mathrm{O}_{2}, \mathrm{HRD}$ input of $1.38 \mathrm{ml} \mathrm{min}^{-1}$ (equivalence ratio $=0.21$ ), and steam input of $1.0 \mathrm{~g} \mathrm{~min}^{-1}\left(\mathrm{H}_{2} \mathrm{O}: \mathrm{C}\right.$ ratio of 0.73 ).

SER values obtained for both fuels were below the $\sim 340 \mathrm{~kJ} \mathrm{~mol}^{-1} \mathrm{H}_{2}$ benchmark for steam reforming of natural gas but above the $\sim 110 \mathrm{~kJ} \mathrm{~mol}^{-1} \mathrm{H}_{2}$ identified as competitive for plasma based systems. SER could be improved by reducing heat loss, recovering and recycling unreacted liquid and gas phase hydrocarbons, and operating the reformer as a fully integrated industrial package.

\section{Acknowledgements}

This work was supported by the Office of Naval Research under grant number N00014-11-1-0391

\section{Works Cited}

[1] Andrews J, Shabani B. Re-envisioning the role of hydrogen in a sustainable energy economy. International Journal of Hydrogen Energy. 2012;37:1184-203.

[2] Petitpas G, Rollier JD, Darmon A, Gonzalez-Aguilar J, Metkemeijer R, Fulcheri L. A comparative study of non-thermal plasma assisted reforming technologies. International Journal of Hydrogen Energy. 2007;32:2848-67.

[3] Mueller-Langer F, Tzimas E, Kaltschmitt M, Peteves S. Techno-economic assessment of hydrogen production processes for the hydrogen economy for the short and medium term. International Journal of Hydrogen Energy. 2007;32:3797-810.

[4] Kothari R, Buddhi D, Sawhney RL. Comparison of environmental and economic aspects of various hydrogen production methods. Renewable and Sustainable Energy Reviews. 2008;12:553-63. 
[5] Yang C, Ogden J. Determining the lowest-cost hydrogen delivery mode. International Journal of Hydrogen Energy. 2007;32:268-86.

[6] Gutsol A, Rabinovich A, Fridman A. Combustion-assisted plasma in fuel conversion. Journal of Physics D: Applied Physics. 2011;44:274001.

[7] Reddy EL, Biju VM, Subrahmanyam C. Production of hydrogen from hydrogen sulfide assisted by dielectric barrier discharge. Int J Hydrogen Energy. 2012;37:2204-9.

[8] Mutaf-Yardimci O, Saveliev AV, Fridman AA, Kennedy LA. Thermal and nonthermal regimes of gliding arc discharge in air flow. Journal of Applied Physics. 2000;87:1632-41.

[9] Paulmier T, Fulcheri L. Use of non-thermal plasma for hydrocarbon reforming. Chemical Engineering Journal. 2005;106:59-71.

[10] Fridman A, Nester S, Kennedy LA, Saveliev A, Mutaf-Yardimci O. Gliding arc gas discharge. Progress in Energy and Combustion Science. 1998;25:211-31.

[11] Nunnally T, Gutsol K, Rabinovich A, Fridman A, Starikovsky A, Gutsol A, et al. Dissociation of H2S in non-equilibrium gliding arc "tornado" discharge. International Journal of Hydrogen Energy.

2009;34:7618-25.

[12] Gallagher MJ, Geiger R, Polevich A, Rabinovich A, Gutsol A, Fridman A. On-board plasma-assisted conversion of heavy hydrocarbons into synthesis gas. Fuel. 2010;89:1187-92.

[13] Kalra CS, Cho YI, Gutsol A, Fridman A, Rufael TS. Gliding arc in tornado using a reverse vortex flow. Review of Scientific Instruments. 2005;76:0251101 - 7.

[14] Piavis W, Turn S. An experimental investigation of reverse vortex flow plasma reforming of methane. International Journal of Hydrogen Energy. 2012;37:17078-92.

[15] Great Green Fleet. 2013. http://greenfleet.dodlive.mil/energy/great-green-fleet/. Accessed: May 7, 2014

[16] ASTM. D 1946 - 90 Standard Practice for Analysis of Reformed Gas by Gas Chromatography. ASTM International. 2006.

[17] Lee S-w, Kusaka J, Daisho Y. Spray characteristics of alternative fuels in constant volume chamber (comparison of the spray characteristics of LPG, DME and n-dodecane). JSAE Review. 2001;22:271-6.

[18] Som S. Advancement in Fuel Spray and Combustion Modeling for Compression Ignition Engine Applications. In: Longman DE, editor. Argonne National Laboratory2012.

[19] Gowdagiri S, Wang W, Oehlschlaeger MA. A shock tube ignition delay study of conventional diesel fuel and hydroprocessed renewable diesel fuel from algal oil. Fuel. 2014;128:21-9.

[20] Kalra CS, Kossitsyn M, Iskenderova K, Chirokov A, Cho YI, A.Gutsol, et al. Electrical discharges in the reverse vortex flow - tornado discharges. 2003.

http://plasma.mem.drexel.edu/publications/documents/ISPC-16-565-Tornado.pdf. Accessed: 8/6/2008

[21] Rollier J-D, Gonzalez-Aguilar Jx, Petitpas G, Darmon A, Fulcheri L, Metkemeijer R. Experimental study on gasoline reforming assisted by nonthermal arc discharge. Energy Fuels. 2008;22:556-60.

[22] Galvita V, Messerle VE, Ustimenko AB. Hydrogen production by coal plasma gasification for fuel cell technology. International Journal of Hydrogen Energy. 2007;32:3899-906.

[23] Pietruszka B, Heintze M. Methane conversion at low temperature: the combined application of catalysis and non-equilibrium plasma. Catalysis Today. 2004;90:151-8.

[24] Box GEP, Hunter WG, Hunter JS. Statistics for Experimenters. 1st ed. New York, NY: John Wiley \& Sons. Inc; 1978. 

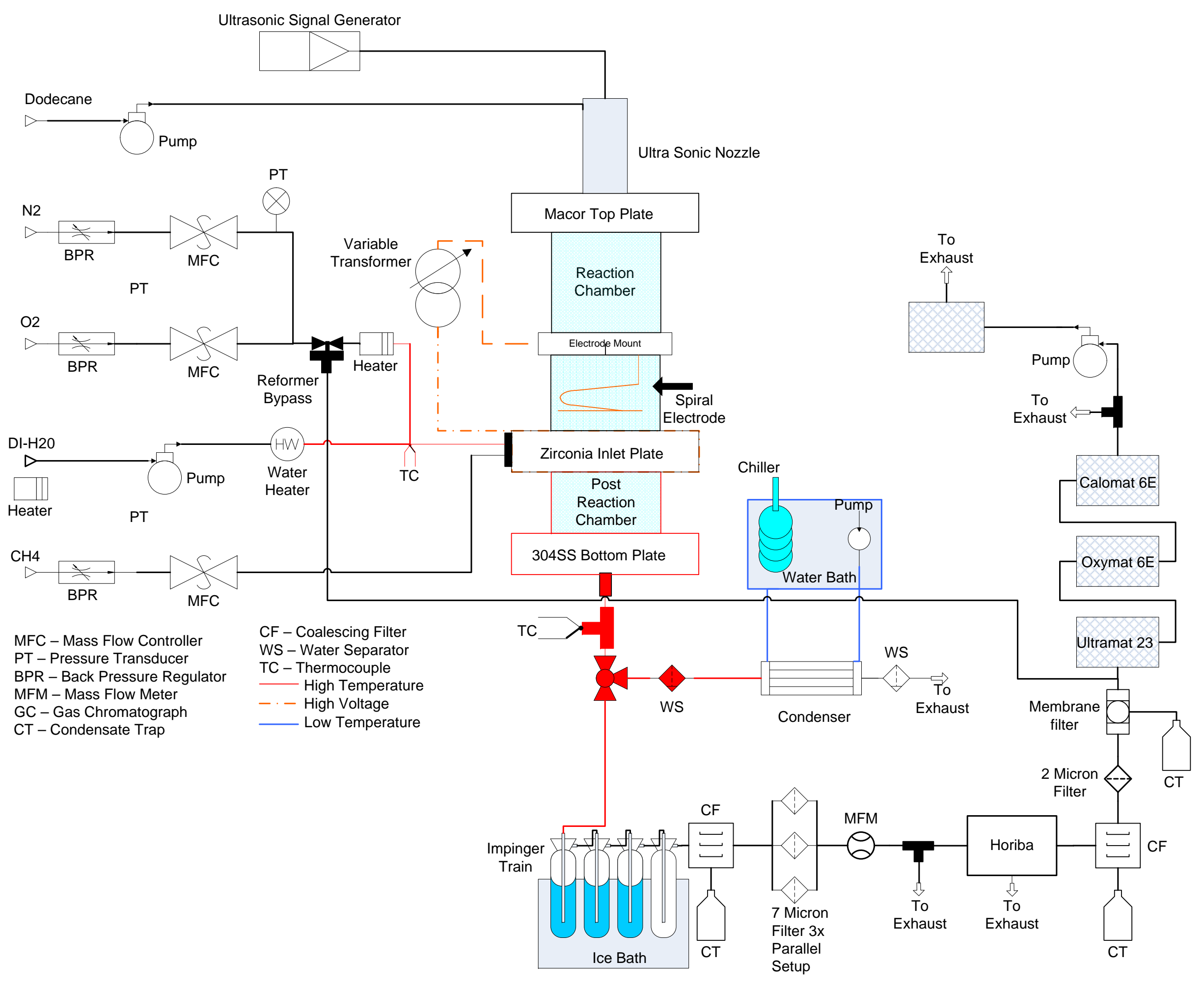


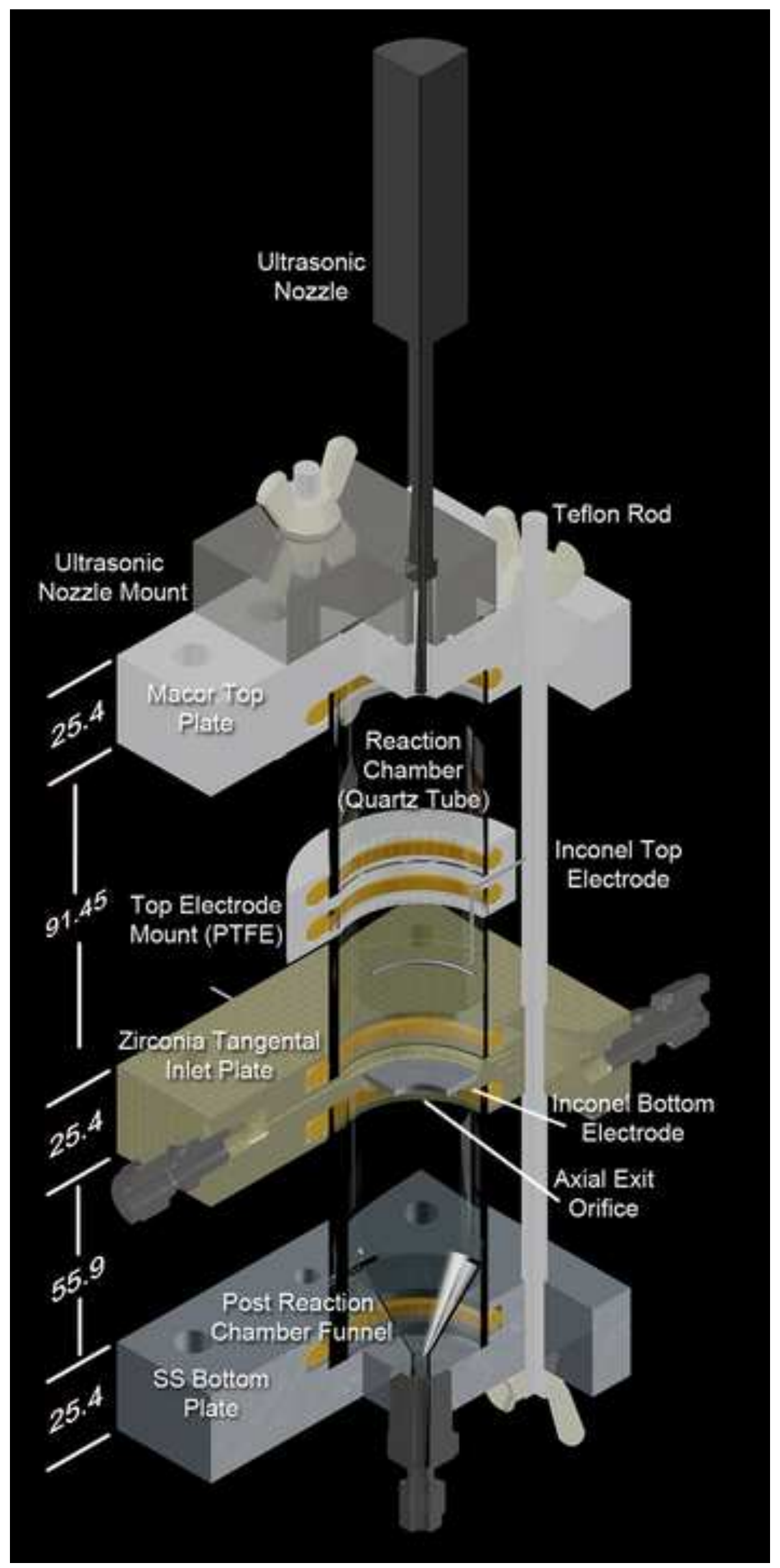




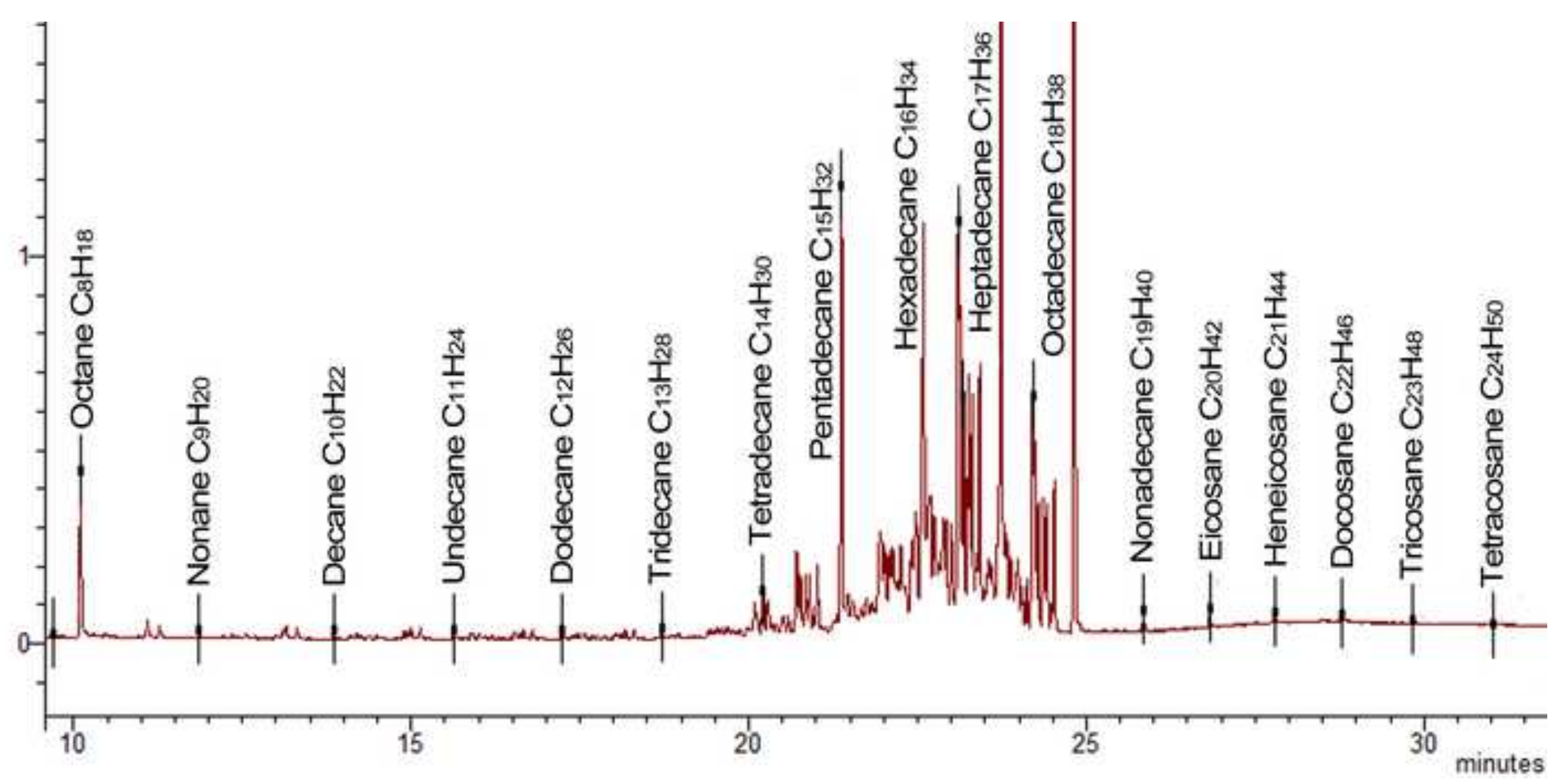



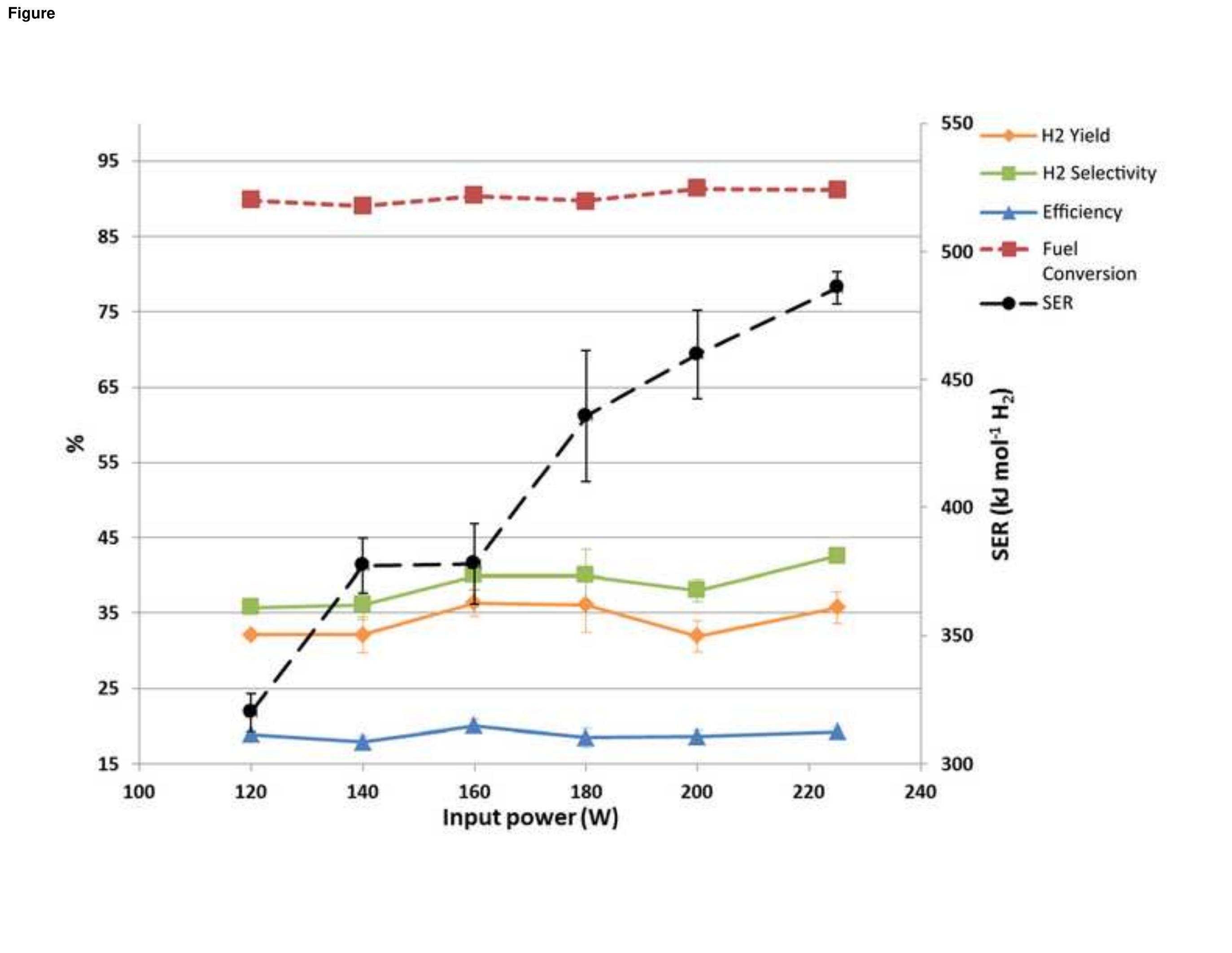

更

更

更

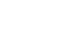

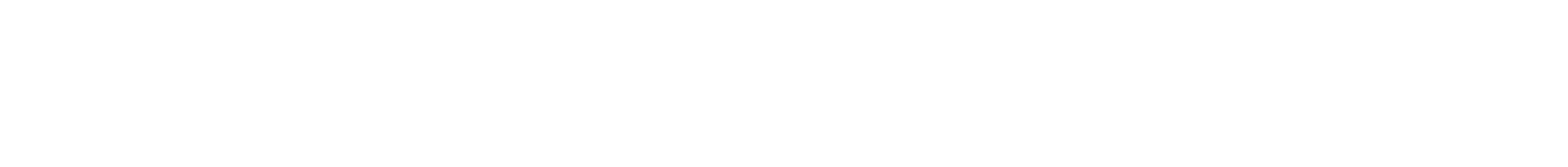

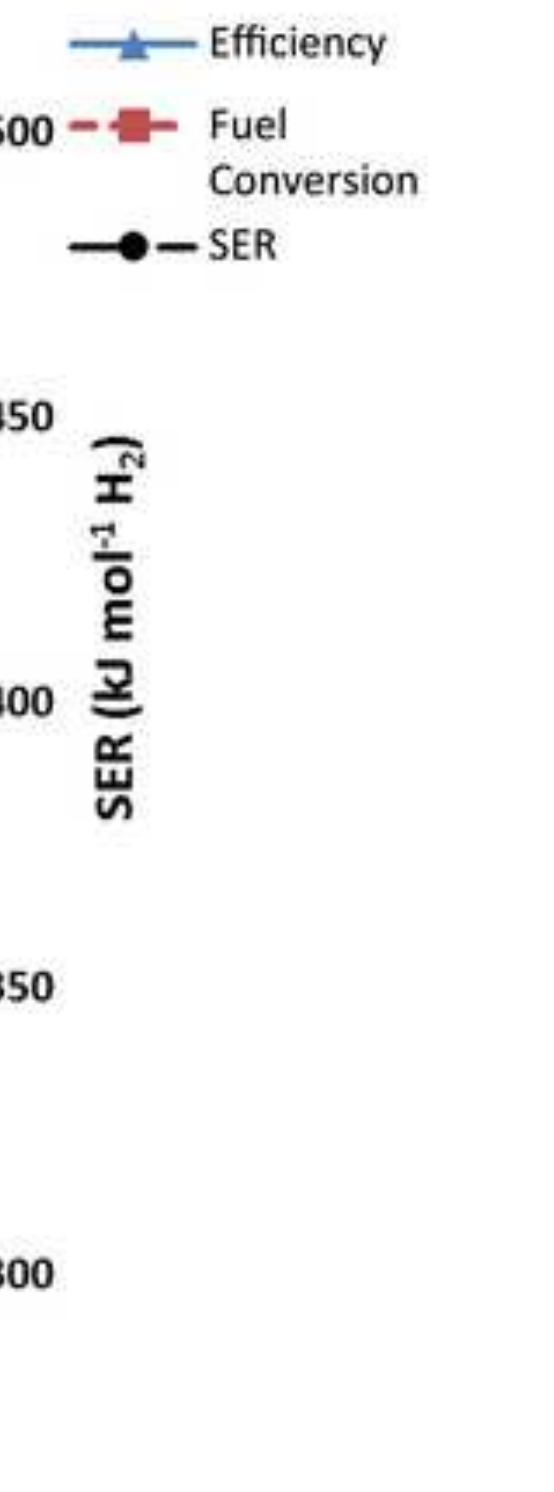




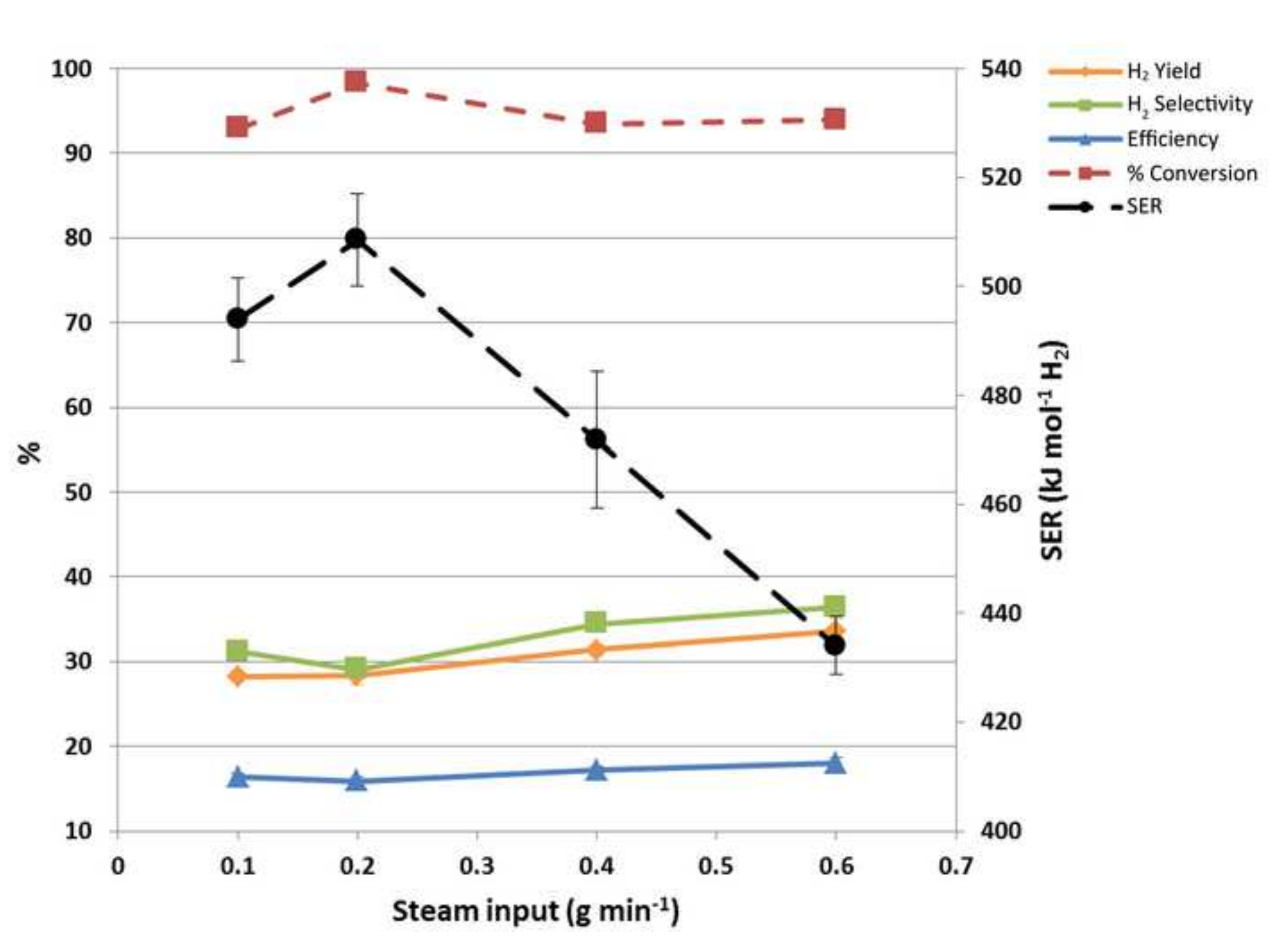




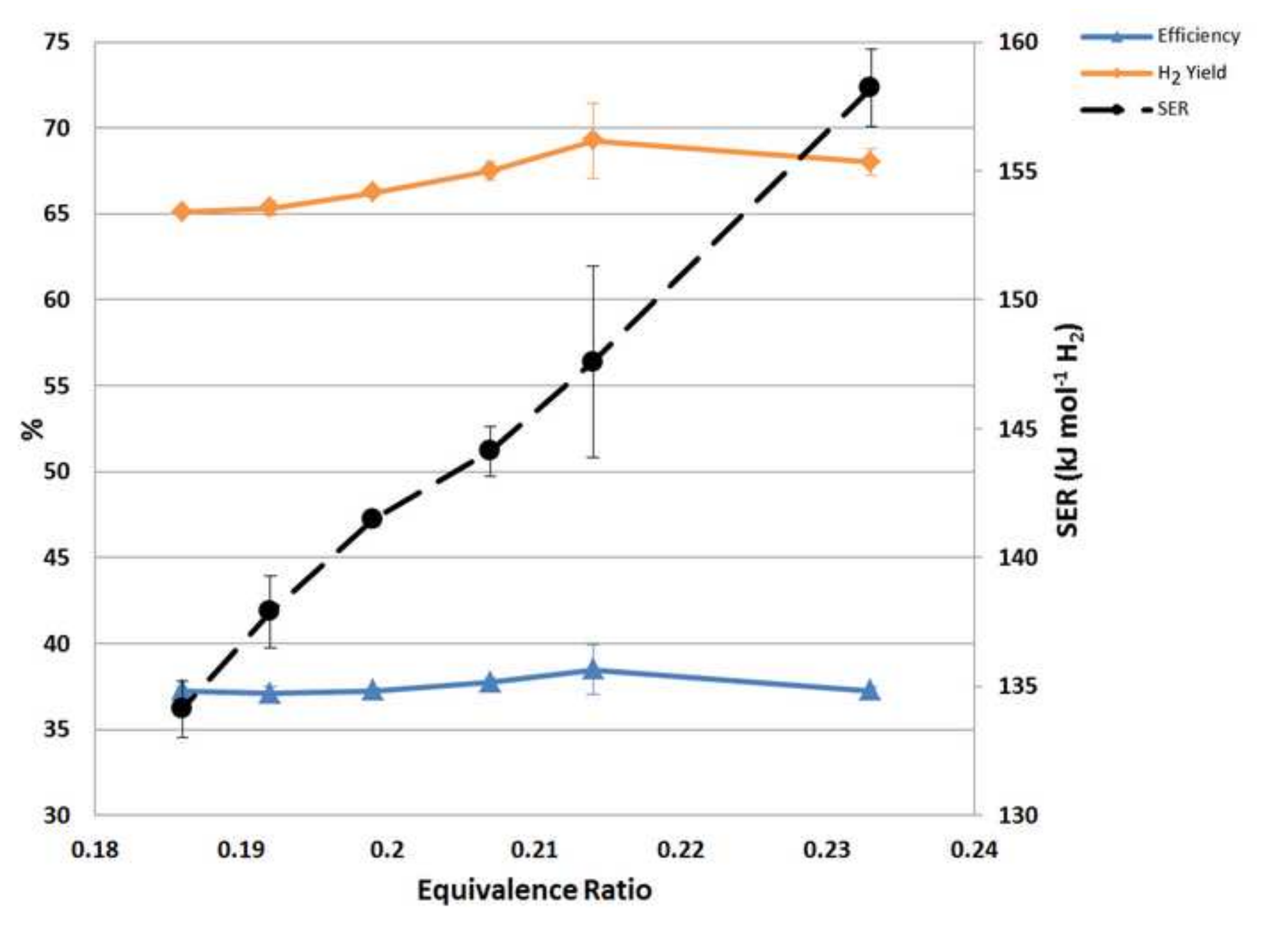

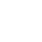

(n)

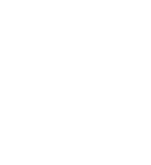

\author{
Equivalence Ratio
}

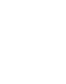

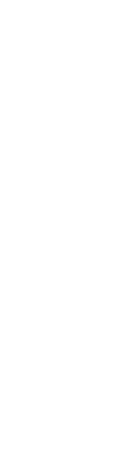

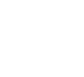

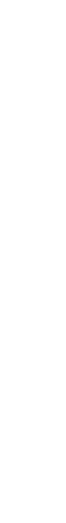

(

$$
\text { - }
$$




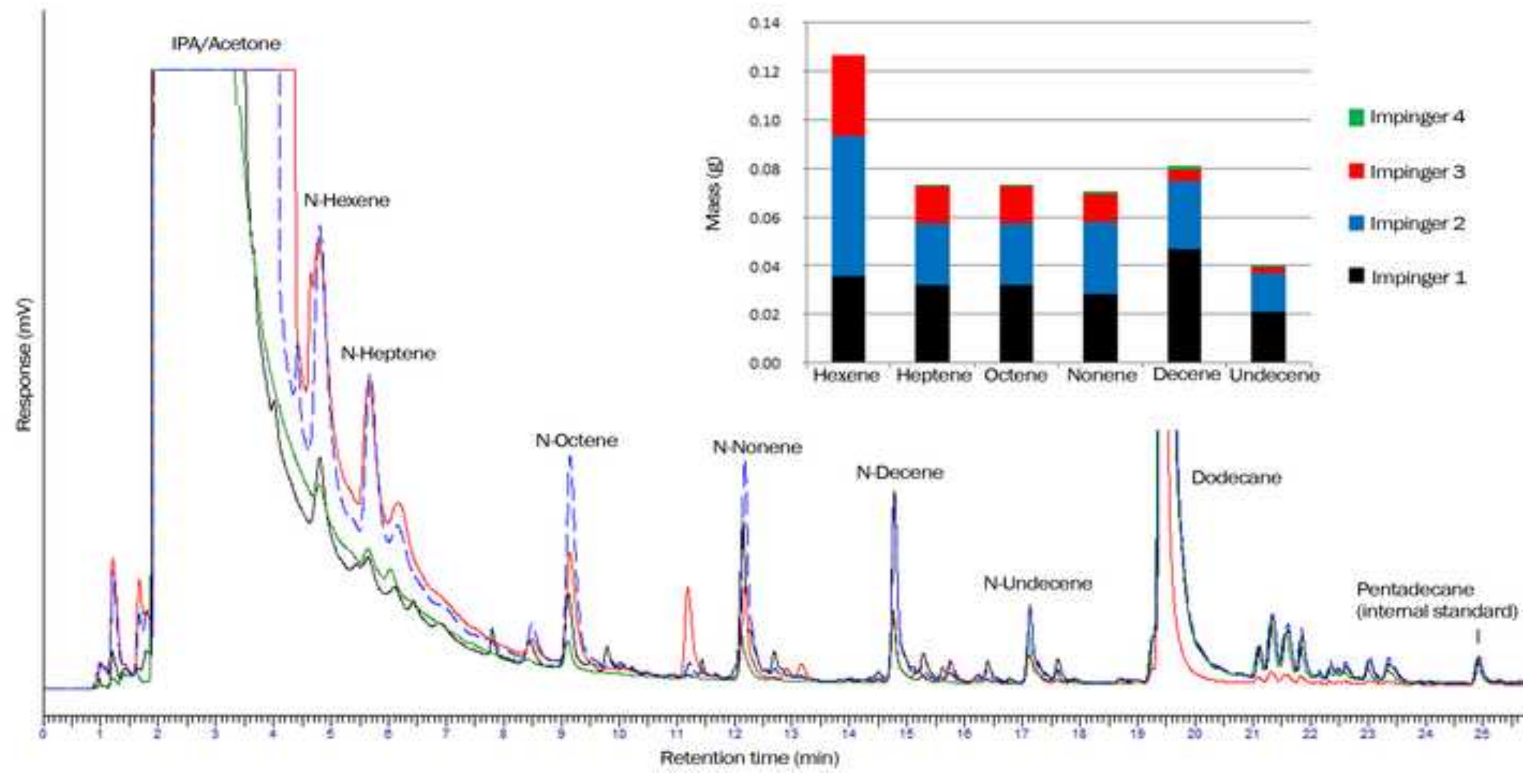




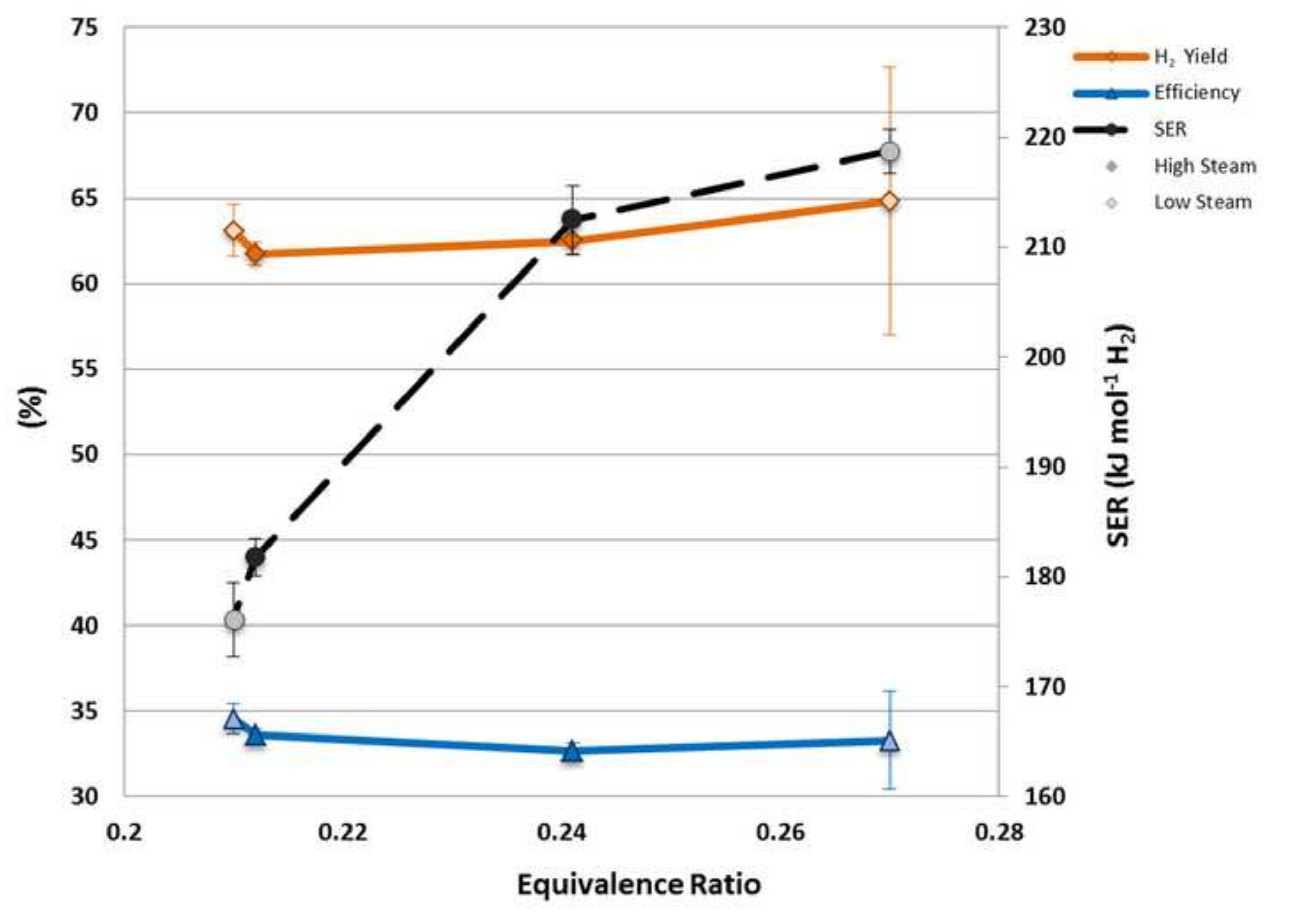

quivalence Ratio

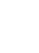

